\title{
Pre-Service Foreign Language Teachers' Awareness of White Privilege
}

\author{
Shannon L. McGowan ${ }^{1}$, Anne L. Kern ${ }^{2}$ \\ ${ }^{1}$ Assistant Professor, Modern Languages \& Cultures, University of Idaho, USA \\ ${ }^{2}$ Associate Professor, Science Education, University of Idaho Coeur D'Alene, USA \\ Correspondence: Shannon L. McGowan, University of Idaho, 875 Perimeter Dr MS-3174, Mosocw, ID, USA
}

Received: December 16, 2015 Accepted: January 4, 2016 Online Published: January 15, 2016

doi:10.11114/jets.v4i4.1250

URL: http://dx.doi.org/10.11114/jets.v4i4.1250

\begin{abstract}
Over the last several years teacher preparation programs have strived to adequately prepare pre-service teachers for more diverse populations in the classroom. However, little research has been done to examine the attitudes of pre-service teachers related to white privilege. This is the qualitative report from a mixed-methods study which examined those attitudes, the quantitative report has previously been published. The quantitative portion employed a pre/post-test survey surrounding interactive activities and found a significant change in participants' attitudes regarding social issues of privilege, such as racism and sexism (McGowan \& Kern, 2014). This paper reports the ways pre-service foreign language teachers examined their understandings of white privilege. Students in a language methods course $(\mathrm{N}=19)$ participated in specific activities to explore how they relate privilege and oppression to their own lives and futures as teachers. A grounded theory approach was utilized to analyze the students' responses to questions regarding the activities. From the analysis, six major themes were discovered. Three themes indicated the affordances pre-service teachers gained from the activities regarding privilege. Whereas, the other three themes indicated possible challenges in regards to privileged thinking. Suggestions for further research include determining the long-term effects of the intervention and extending the instructional intervention length.
\end{abstract}

Keywords: white privilege, pre-service foreign language teachers, privilege and oppression awareness, equity issues in education

\section{Introduction}

In 2011, approximately $82 \%$ of the teaching force and $52 \%$ of the student body in the United States identified as white (National Center for Educational Statistics, 2015). These numbers indicate a significant white teaching force instructing a large student population of color. Although a current trend in education is multicultural education, it is still likely that there is a cultural gap between white teachers and their students of color. This gap may be broadened by white teachers lacking the knowledge of how white privilege manifests in education and among teachers. In this way, issues related to privilege may be inadvertently creating a hostile and unequal classroom environment for both teachers and students. Thus, teacher education programs need to explore and discuss white privilege among pre-service teachers.

\subsection{Review of the Literature}

Seminal work by McIntosh (1988) defined white privilege as "an invisible weightless knapsack of special provisions, assurances, tools, maps, guides, codebooks, passports, visas, clothes, compass, emergency gear, and blank checks" that white people carry and people of color do not (p. 125-126). People who identify as white are afforded advantages that people of color do not have (McIntosh, 1988). These advantages range from simple expectations of not being followed around a store by the clerk to more blatant discrepancies such as lower interest rates when applying for a loan. One of the most central advantages is that white people have the privilege to choose whether or not to engage in racial discourse and that, according to McIntosh (1988), allows white people to remain ignorant that racial issues are endemic. However, white privilege does not only benefit the individual; it creates belief systems.

One's beliefs are based on societal norms, and the "characteristic of the privileged group define the societal norm[s]" (Wildman, 2005, p. 247). In this way, the opinions, standards, and expectations for North American society are often defined and maintained by whites through white privilege. As a social construct, white privilege becomes an ideology and is inherently hierarchical (Hays \& Chang, 2003). Even though whiteness may not be overtly seen by white people, it is an inherent and normalized part of our society (Picower, 2009). 
Within the school system, this ignorance blinds white teachers to the privileges they have associated with being white. Teachers already hold a position of power over their students due to the hierarchy of the educational system. Yet based on their membership in the dominant group, white teachers may have additional cultural power over their students of color since whiteness and racism are entrenched in our schools (Vaught \& Castagno, 2008). Along with the systemic racism in schools white teachers have had life-long support of their beliefs related to people of color, yet by developing "cultural competence and socio-political consciousness" teachers can become better educators (Picower, 2009, p. 199). Through the exploration of one's own beliefs and perceptions related to his or her own whiteness, it is possible to change those beliefs and perspectives (Marx, 2004). Additionally, the awareness that comes from teachers' reflections on their own prejudices and beliefs can lead to a more equitable classroom and a multicultural perspective regarding students' behaviors (Weinstein, Tomlinson-Clarke, \& Curran, 2004).

Many white teachers tend to be ignorant of their membership in a racial group, and therefore, do not identify as racial beings (for example: Dalton, 2012; hooks, 2012; Picower, 2009) whereas the identity of students of color includes such characteristics as ethnicity, social class, culture, and background (Porto, 2010). However, it is unlikely white teachers acknowledge and understand the role whiteness plays in the classroom. Therefore, it is imperative that pre-service teachers be explicitly taught how to examine their own whiteness in order to understand its impact in the classroom.

Unfortunately, the concepts of white privilege and whiteness as a race are seldom taught in teacher education programs, even in those programs that include multicultural education (e.g. Chou, 2007; Cochran-Smith, 2003; Menchaca, 1996). Within a teacher education program one goal is to encourage pre-service teachers to learn how to teach every student, yet this does not appear to be happening as most teacher education programs are not designed to prepare future teachers to teach in culturally responsive ways (Hayes \& Juarez, 2012). Additionally, due to a lack of instruction that addresses inequalities in the system based on white privilege, many teacher education programs simply perpetuate the systemic inequality. Hence, culturally responsive teaching should be included as an integral part of all teacher education programs (Gay \& Kirkland, 2003). Culturally responsive teaching includes a critical consciousness regarding race, culture, and ethnic diversity as well as a critical reflection of the teacher's own racial and cultural competences (Gay \& Kirkland, 2003).

Another issue facing teacher education programs is that many of the current faculty are white professors who perpetuate the dominant culture's beliefs, values, and perspectives (Hayes \& Juarez, 2012). Research has indicated that even when pre-service teachers were eager to learn about diversity issues, their programs tended to reflect the personal interests of the professors, which often minimized multicultural content (Sleeter, 2001). Therefore, there needs to be a way for pre-service teachers to explore, discuss and create their own understandings of multicultural topics.

However, this exploration of multicultural topics may cause an array of emotions for pre-service teachers, yet they may not know how to handle them (Solomon, Portelli, Daniel \& Campbell, 2005). The range of emotions can include "anger, guilt and paralysis" (p. 164) which may lead to a disengagement of anti-racism work (Solomon, et. al, 2005). To avoid this disengagement, teacher education programs must offer pre-service teachers a safe learning environment in which they can freely explore and reflect on their emotions and feelings regarding white privilege (Solomon, et al., 2005).

It is possible that by learning about privileges associated with white privilege, pre-service teachers will have a clearer understanding of the implications it can have on their students (McGowan \& Kern, 2014). McGowan and Kern (2014) found that through privilege-focused activities, pre-service teachers' attitudes regarding social issues (sexism, racism, heterosexism, and Christian privilege) significantly changed. This qualitative inquiry expands on the quantitative work by McGowan and Kern (2014) by understanding the underlying reasons behind the change.

The focus for the qualitative portion of the study examined the ways in which instructional activities related to white privilege impacted pre-service teachers' awareness of privilege. These activities included student written responses to prompts regarding white privilege, an intervention lecture on the aspects of white privilege and multicultural education, a hands-on activity to determine each students' place within the white privilege hierarchy, an in-depth question and answer session regarding the activity, as well as the viewing of short clips from a documentary that focused on white privilege. The details of the activities are discussed below in the methods section.

\subsection{Present Study and Statement of the Problem}

Pre-service foreign language teachers are required to have an extensive understanding of the language and culture they intend to teach (American Council of the Teaching of Foreign Languages [ACTFL], 1999). Kubota, Austin, and Saito-Abbott (2003) note that through the understanding and learning of a new culture and language, ethnocentrism and stereotypes can be reduced. Therefore, as foreign language pre-service teachers begin to explore another culture, they may begin to critically examine their own. This may lead to a greater understanding of the privileges afforded them due to their membership in dominant culture (Kubota, et al., 2003). Yet, although the standards set forth by the American Council of the Teaching of Foreign Languages (1999) require pre-service language teachers to have a vast exposure to a 
foreign culture, it is not well understood if that exposure transfers into a better understanding of the culture in which they hope to teach. It is projected that by the year 2025 , only $58 \%$ of the total U.S. population will identify as white (Aud, Fox, \& KewalRamani, 2010). As the demographics within the United States change, pre-service teachers need to understand the historic and current role dominant American society plays in the school system. Through an examination of their own whiteness, pre-service teachers can begin to learn how to successfully incorporate all cultures into the classroom.

Based on the cultural knowledge requirements for pre-service foreign language teachers (ACTFL, 1999), it was speculated that pre-service language teachers' study of foreign cultures impacted their awareness and attitudes regarding their own culture and the privileges associated with it. With this in mind, the intent of this qualitative portion of the study was to determine the ways in which instructional activities and an in-depth discussion about white privilege within a foreign language methods course impacted the pre-service foreign language teachers' beliefs about privilege and oppression in American society.

\section{Method}

\subsection{Participant Sample}

Students enrolled in a secondary language methods course were selected for this study. Following proper IRB protocols, all students agreed to participate $(\mathrm{N}=19)$. The course was part of the required curriculum in a teacher preparation program in a small, rural university in the inland Northwest. The majority of the participants identified as white (74\%) which aligns closely with the national statistic of in-service teachers (82\%). Table 1 shows the breakdown for gender and race of the participants.

Table 1. Participant demographics based on gender and race.

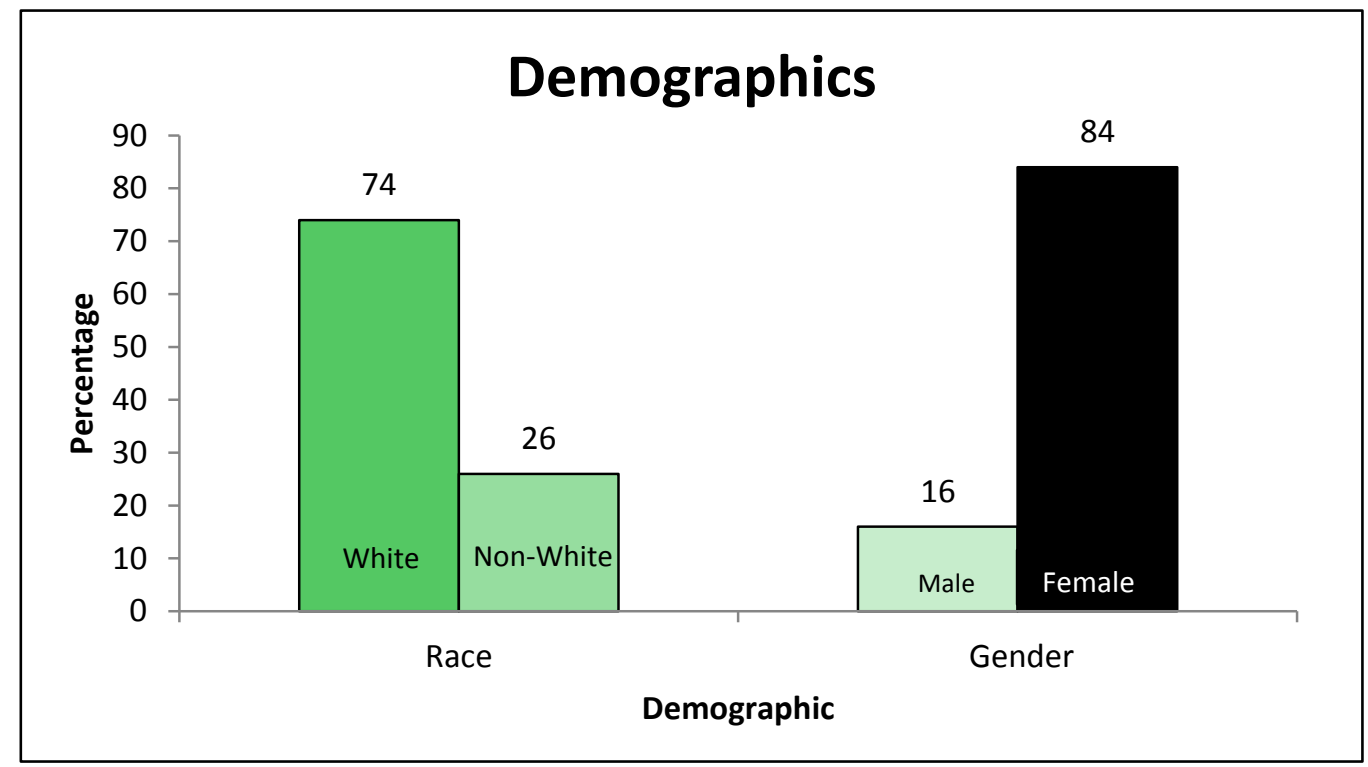

In addition to the methods course, students must also complete a series of courses as a part of the teacher education program. These courses must be successfully completed prior to enrollment in the methods course. The required courses include: Contexts of Education; Learning, Development, and Assessment; and Teaching Culturally Diverse Learners. In each course, diversity and multicultural education are addressed in a variety of ways (i.e. classroom management, assessment, learning styles, etc.). Additional courses, dependent on the pre-service teacher's degree plan and major, may also be taken prior to the methods course.

\subsection{Sampling Procedures and Protocol}

\subsubsection{Measures}

This study consisted of both quantitative and qualitative research. The quantitative portion examined participants' scores on a pre-test and post-test (The Privilege and Oppression Inventory) between which the activities listed in this qualitative study took place. The results of the quantitative portion of the study were published by McGowan and Kern (2014) in the Journal of Education and Training Studies. The quantitative data indicated a significant difference between the participants' attitudes regarding social issues such as racism, sexism, heterosexism, and Christian Privilege based on the instructional activities of the qualitative portion. The qualitative data concentrated on the activities listed below to determine the reasons for the significant difference on the pre- and post-test. These activities focused on the 
specific research question: What are the affordances and challenges of focused instructional activities and an in-depth discussion about white privilege on the awareness of pre-service foreign language teachers regarding privilege in the public education system in the United States?

\subsubsection{Protocol}

For this study, the participants engaged in a three-hour class which focused on instruction about and activities to explore white privilege and oppression. The class consisted of the following segments:

\section{A brief lecture involving the following:}

a. The definition and historical creation of white privilege within the U.S.

b. The ways in which white privilege is maintained in current U.S. systems.

c. The definition of the deficit model ${ }^{1}$ and colorblindness ${ }^{2}$ as they relate to education.

d. The ways in which the deficit model and colorblindness are manifested in the U.S. education system.

2. Active participation in an adapted version of the statements from the "The Privilege Walk" (appendix A). The Privilege Walk is an interactive experience in which participants respond to questions that deal with white privilege and oppression by stepping forward or backward from a starting line based on their experiences of that question (e.g. If you were born in the United States take one step forward.)

Note: Since this study was conducted, criticisms have arisen regarding how the privilege walk

perpetuates privilege by continuing to oppress and marginalize people of color. The literature for these criticisms is limited.

3. A face-to-face question and answer session in which participants were asked follow-up questions adapted from another example of "The Privilege Walk" immediately followed the exercise (Appendix B). The open-ended questions, such as "What are your general reactions to this exercise?" were asked and participants were given unlimited time to respond. In addition, each participant was given the option whether or not to respond to each question. The qualitative data is derived mainly from this session.

4. A viewing of short excerpts from The Color of Fear (1994).

Note: This documentary focused on racism within the United States from 6 men's perspectives. Due to time constraints, only two short clips were used. They were chosen based on their explanation and discussion about privilege from men of color. These clips were used solely for the purpose of examining racial issues, not other social issues such as sexism.

In addition to the above class-time activities, participants also responded to questions posted on a confidential blog. These blog questions were asked over a one-month period and the responses were used within the qualitative analysis. Examples of the blog questions included asking participants to define white privilege, to offer examples of times in which they felt oppressed, and to share their reactions to the activities above.

\section{Results}

The qualitative data for this study were based on the video and audio taped large group discussion that took place immediately following the privilege walk. Following IRB protocol, all participants agreed to the video and audio tape session. Each participant was asked five general questions (Appendix B) and were then given the option whether to respond or not regarding their thoughts and feelings about the question. In addition, the confidential blog posting specific to the privilege walk exercise asked the participants to respond to two questions 1) In what ways does your awareness of white power and privilege affect your daily life, and 2) In what ways does your awareness and understanding of white power and privilege affect your life as a teacher? Using a grounded theory methodology, the results found three challenges and three affordances to address the research question. Figure 1 shows the research question along with the themes found in the study.

\footnotetext{
${ }^{1}$ Deficit model: "the perspective that minority group members are different because their culture is deficient in important ways from the dominant majority group... The deficit model asserts that racial/ethnic minority groups do not achieve as well as their White majority peers in school and life because their family culture is dysfunctional and lacking important characteristics compared to the White American culture." (Salkind, 2008).

${ }^{2}$ Colorblindness: "Educators who endorse the color-blind perspective believe that the racial group membership of students should not be considered when making decisions about curriculum and teaching and that the best way to promote racial equality is to create a color-blind society." (Rudnick, 2012).
} 


\subsection{Results}

Six main themes arose from the discussion and blog postings regarding the instructional activities. Although the themes are numbered, this system is for organizational purposes only and does not reflect the importance of each theme.

Figure1. Concept map showing the major themes as they related to the research question.

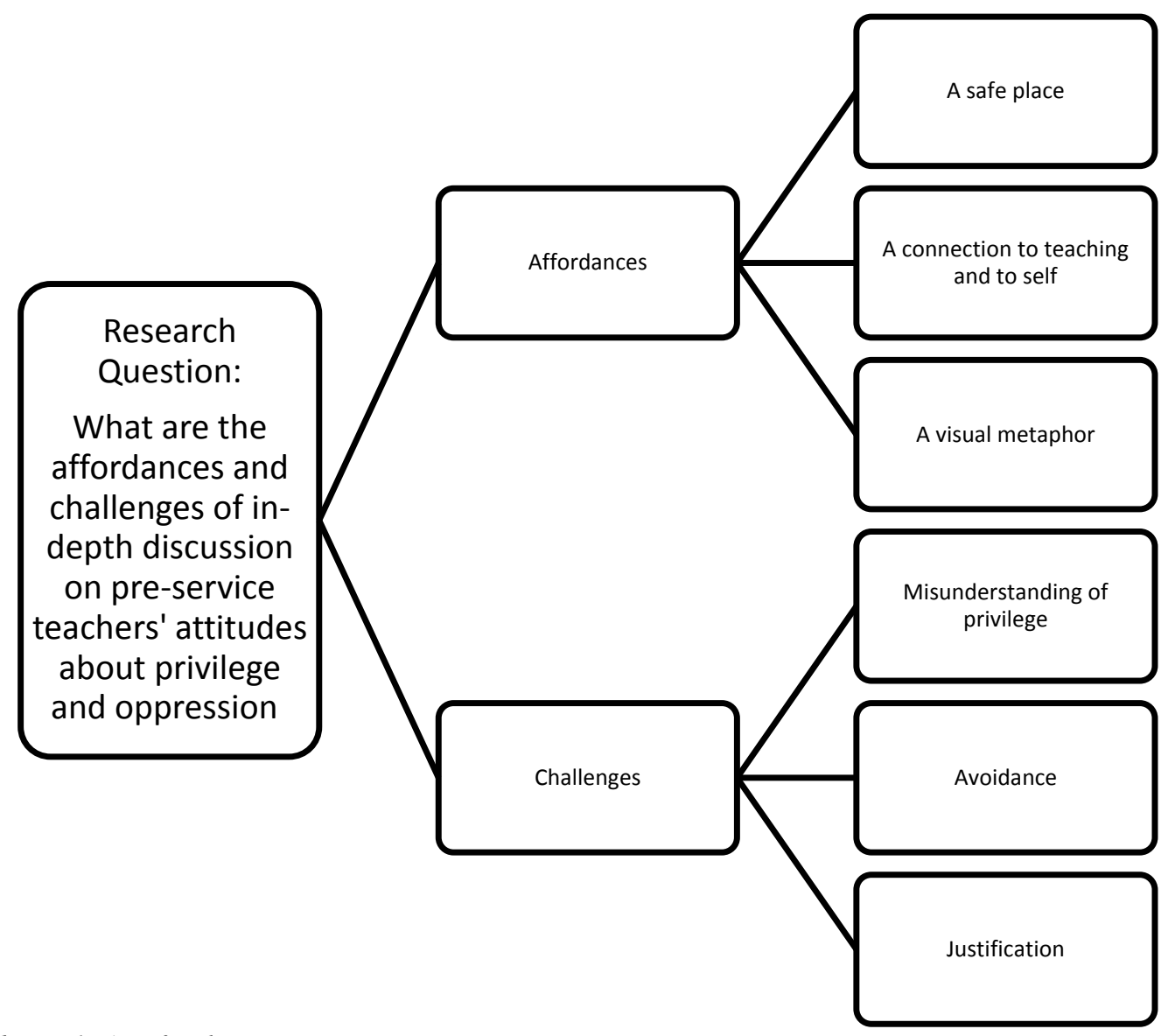

\subsubsection{Theme 1: A safe Place}

A safe place is vital when discussing difficult issues as it "allows students to feel secure enough to take risks, honestly express their views, and share and explore their knowledge, attitudes, and behaviors" (Holley \& Steiner, 2005, p. 50). Overall, students who felt they were in a safe place were able to learn more about others while being challenged to build on their own viewpoints and self-awareness (Holley \& Steiner, 2005).

In this research, two concepts related to the theme of a safe place emerged. The first and most common one involved participants remarking upon how they felt about the current environment in which they were having the discussion. There was a general consensus of a safe place or freedom to share personal information, even without any request for it. The second theme included the pre-service teachers' acknowledgment and understanding of the importance to create a safe place in their future classrooms.

“...I'm super hesitant about talking about my religion. I admitted to a supervisor one time and was immediately out casted just because I'm a practicing Pagan...I won't admit openly to anybody unless asked." (Note: this participant was not asked directly to discuss religion.) (Asian, Male)

"I think I'm kind of the same way as you, when it comes to religion and sexual orientation and stuff that seems too personal, and even with people I know I don't usually tell them... This is probably like the second time in like a class setting that I've come out..." (Latina, Female)

"This is a great model of what we hopefully aspire to be is to create an environment where our students can feel safe and open and able to discuss things..." (White, Female)

"As a teacher, I can just try my best to keep an open relationship with my students where they can feel comfortable talking to me about issues they have..." (White, Female) 


\subsubsection{Theme 2: A Connection to Teaching and to Self}

This theme involved the participants' understanding about how this activity not only connected to their future careers as teachers, but also how it positively impacted them personally. Research has shown the importance of incorporating whiteness issues into curricula, personal reflection regarding white privilege, and a critical consciousness to improve attitudes towards racial issues (e.g. Gay \& Kirkland, 2003, Marx, 2004, Milner, 2006). Through the participation of the privilege walk and the discussions that followed, the pre-service teachers were able to reflect on their own whiteness in relation to their roles as future teachers.

"When I was making my lesson plans, I was looking at some old materials I made when I was interning at the school here and, um, something that this white privilege talk has made me aware of, I was looking at some materials I've made that was for appearance - pictures of, like, women with short hair and long hair and stuff, and everyone I chose was white. And I look back on it and I was really embarrassed because it was like three or four pages of all these different people and it was just white people. And the class that I brought that to, it was mostly Chinese or Saudi Arabian and I didn't even think anything of it until now." (White, Female)

"...I was thinking about my lesson plans... and on some of them, I was, what I was coming up with the comparisons with the target language and culture with their own culture and I think I was making assumptions that everybody was kind of in the same place and had the same experiences and so it actually occurred to me that on some of my lesson plans I may not be able to make those same assumptions." (White, Female)

"I thought it was a very memorable experience to look back on in the future." (White, Female)

"I agree. I learned a lot. I had no idea this was going to relate to teaching so much...I will totally use it and I got a lot out of it personally and I think it's great." (White, Female)

“...I am able to better understand...my awareness and understanding will hopefully promote an awareness in others..." (White, Male)

"I have learned that white privilege affects both others and myself every day." (Latina, Female)

\subsubsection{Theme 3: A Visual Metaphor}

Participants noted that the privilege walk activity created a visual metaphor for privilege. Based on where they ended up due to stepping forward or backward allowed them to see their privilege in relation to their peers. This visual metaphor offered many participants the ability to "see" the advantages they have had due to white privilege. This visual representation of diversity has been shown to help students in the classroom see their differences in a different way, which can positively impact classroom environments and student interactions (Sassi \& Thomas, 2008).

"Uh well once again I wasn’t too surprised where I landed I mean the first question, me being the only white dude here, I kinda saw where it was going. What I did find really surprising looking back and not seeing how many people were behind me but how far, I just I never really kinda realized how that worked."

(White, Male)

"What I found really impactful was that, uh, I was a person who stepped forward quite a bit and I couldn't see the people behind me without kinda looking around and I thought that was a really apt visual metaphor...I know they're back there ....all I can see is the people that have done better than me... I can't see those people" (White, Female)

"From the discussion after the privilege walk, and maybe especially from the clips from the video, showed me things I hadn't seen or thought of before. I understand that that in itself is an example of white privilege in action." (White, Female)

"Uhm I kind of said that I was about where I thought I'd be. I stepped forward on questions I didn't always step back so it was kind of like one step forward, two back, one forward, two back, I think I was like four or five paces behind the line, so that was kind of interesting." (Latina, Female)

"Both activities were eye-opening and I've definitely thought a lot more about different aspects of my life in relation to others' that I've never considered before." (White, Female)

\subsubsection{Theme 4: Misunderstanding of Privilege}

While discussing their physical placement during the privilege walk, many participants focused on their individual backgrounds, upbringings, and parent's socio-economic status to define privilege. In this way, the participants focused more on gender and socio-economic status. This type of behavior is a common response when one is confronted with racial issues (Gay, 2010). When discussing these types of issues, many pre-service teachers emphasize certain "aspects of diversity (such as gender, social class, and individuality) that [are] not as troublesome for them" (Gay, 2010, p. 146). 
This indicated the common misconception of white privilege as an entitlement and not as a systemic issue based on racism and oppression. By defining privilege as the entitlements of their backgrounds, the participants were able to minimize their acceptance of those privileges. In this way, the participants were able to justify their placement from the starting line in the privilege walk activity as an individual situation and not as a systemic one.

“...I was basically where I expected to be because, I mean, my parents weren't super rich but they weren't poor either." (White, Female)

"I was more back than I thought I'd be because I grew up in a very privileged home and both my parents had a college education and are also very privileged..." (White, Female)

“...it was right where I expected to be. My family is rather stable and while we're not the richest of the rich...it's about where I was." (White, Female)

"I knew where I was going to end up because of my childhood upbringing." (Asian, Male)

"... and knowing now that there's differences in how we grew up and where we came from and, um, just to be accountable as teachers. Just to make sure that we are mindful of that and embracing all the differences in the classroom." (White, Female)

\subsubsection{Theme 5: Avoidance}

Another obstacle that arose was the participants' discomfort with discussing race issues. Many white participants simply tried to avoid dealing with the systemic racism of privilege by emphasizing the ways in which they had felt marginalized or oppressed, including using their race and gender. In addition, on the confidential blog, many noted that white privilege had no impact on them at all. By adopting this reverse racism perspective, the participants mistakenly viewed their experiences as having been racist and oppressive, and in doing so negated the actual experiences of people of color (e.g. Gay \& Kirkland, 2003).

Another common avoidance tactic was to express feelings of guilt or shame. This tactic tends to change the focus of the conversation away from racial issues altogether (Daniel Tatum, 1992). One interesting phenomenon occurred when white participants conveyed shame or guilt; the students of color in the group attempted to alleviate those feelings for the white participants by excusing the current generation's involvement in systemic oppression. Although white guilt tends to negatively impact racial discussions, it can also lead to positive actions by white people wishing to do something about the oppression (Iyer, Leach, \& Crosby, 2003). One of the biggest challenges in dealing with racial issues is overcoming student avoidance and resistance in order to fully examine these topics and advocate for change. This theme clearly indicated that pre-service teachers need to engage in more than one lesson in privilege and oppression in order to break away from the avoidance of these topics.

\section{Avoidance through personal stories:}

“...when I was the minority being a white female with blonde hair in Costa Rica really put a target on my back...so, there's kind of that reverse thing too." (White, Female)

“...if I stayed in my home town I can stay out to the morning. I don't know why I'm very scared in the dark in the United States." (International student from Taiwan, Female).

“...where you talked about with food, I've seen that and I was on the other end of it. Um, we do Christmas baskets every year down where I'm from... we just go around and give them to the kids and families...I remember just this one house.. parents weren't home, there were two kids, there was no furniture, cupboards were bare, everything like they had nothing... and we went back and got them more because of that.. I cried." (Participant did not recognize this story perpetuated the "saving" of oppressed people). (White, Female)

\section{Guilt and/or shame about their placement in the privilege walk/regarding oppression:}

“...but at the same time, I feel kind of guilty.” (White, Female)

"I couldn't help but feel guilty realizing I'm ahead of so many people" (White, Female)

"I was pretty far forward and I felt like a jerk." (White, Male)

"And I wanna speak to people that say they feel bad because I don't think you should feel bad because they're elements out of your control...I don't think you should feel bad." (Latina, Female)

“... and you guys have said that it kind of makes you feel bad, you shouldn't, really.” (Asian, Male)

From the blog (Note: entries were confidential and no demographics were available for this section).

“...white privilege doesn't seem to affect my daily life much at all...For some it may be daily, and for some not at all..." 
"In my daily life, I usually am not aware of the effects of White Privilege."

"I don't know how white privilege affects my daily life."

"I knew white privilege existed but I never really payed [sic] too much attention to it. I don't see it happening or affecting my daily life in a big way."

\subsubsection{Theme 6: Justification/Denial}

The final theme involved the ways in which participants tried to justify their privilege. They emphasized their lack of control over their placement in the privilege walk, and excused away the privilege as something they did not earn. It appeared easier to do this than to attribute their placement to the systemic privilege prevalent in our society. The reasons they gave for a position further ahead of their peers on the privilege walk included their upbringing or their parents' choices in life. They neglected to recognize the part white privilege played in their lives.

Since many whites tend to see society as an equal and level playing field (Gay, 2010), the participants' justifications sanctioned the maintenance of their positive social identity without compelling them to acknowledge how they were enforcing modern racist thought (Branscombe, Schmitt, \& Schiffhauer, 2007). This behavior aligns with the belief in a meritocracy; the notion of a just society and that individual efforts are fairly rewarded (Daniel Tatum, 1992). By using this belief in individualism and meritocracy, the participants lacked the critical consciousness necessary to completely understand racial issues (Castro, 2010). On one hand, they claimed they had not earned the privilege, as it was due to their upbringing, yet on the other, they acknowledge a need for hard work and effort to get ahead.

“...like someone said, we didn’t decide on our backgrounds. We didn't have any influence on it.” (White, Female)

“...factors that were out of our control, so like, our past, I mean, none of us could control these things so, like, we all kind of had, I don't know... I just thought it was interesting because, um, like, I didn't do anything to be up there and yet I was." (White, Female)

"Each person comes from a different living situation that plays either to their advantage in society or disadvantage and it is something that we do not necessarily always have control over....I wish to believe that we are all on the same level or maybe even that when we are not on the same level we can all work to be on the same level." (Asian, Male)

"I do believe in a couple of systems: pay it forward, and help those who help themselves." (White, male)

“...it was very sobering to be on the very front line, and um, it was uncomfortable because I didn't do anything to deserve to be there." (White, Female)

\section{Discussion}

This research included two data sets, quantitative and qualitative. The quantitative data published by McGowan and Kern (2014) indicated a significant increase in pre-service foreign language teachers' attitudes about privilege and oppression after their participation in the focused activities. The qualitative data support those findings by offering three affordances which increased the participants' awareness and insight of issues surrounding white privilege. However, the qualitative data also indicated three challenges that showed participants' resistance in actively examining their own whiteness. Nevertheless, with continued work, the participants may begin to lessen their resistance and critically examine these types of issues within their own lives (Gay \& Kirkland, 2003). One participant summarized the experience this way:

I never really thought about [white privilege]. At least not in the same way as I do now. I was more aware of racism and blatent [sic] ignorance/judgement [sic] of people who were not white or born in the U.S. I never really considered that the systems within the states, and our own subconscious preconceptions were constantly working against anyone that was different. I now think about white privilege a lot more. I have had quite a few discussions about it with friends. I am more alert, and more thoughtful about how I judge others.

In conclusion, instructional activities focusing on white privilege did have an impact on pre-service foreign language teachers' awareness and attitudes of privilege. Based on these findings, and within the current social setting, it is imperative that teacher education programs examine pre-service teachers' attitudes and awareness towards privilege and oppression. Additionally, the impact of those attitudes on student outcomes should also be explored. This research is merely the tip of the iceberg concerning teacher education programs' capabilities in educating pre-service teachers to successfully teach all students. In order to achieve a more just educational system, teacher education programs, along with schools, need to address the privilege and oppression that exist within the system and allow for teacher exploration to deal with these social issues. 
As the results of this study indicate, a one-time intervention regarding race, privilege, and oppression did have an impact on the attitudes of pre-service teachers. It was through the examination of white privilege that the pre-service teachers became aware of the social issues surrounding education, and the ways in which their own whiteness could impact their future students. Therefore, based on this study and the literature, all teacher education programs should include a critical examination of white privilege for all pre-service teachers. Only by doing so can we hope to create an equal educational system for all students.

\subsection{Limitations}

During the process of this research, four main limitations emerged. They are not mutually exclusive as more than one could be addressed within one replication of this work. The three main limitations to this study are as follows 1) Intersectionality was not addressed, 2) The longitudinal impacts of the study, 3) Lack of transferability to other countries, and 4) My own whiteness.

\section{Oxford Dictionaries online defines intersectionality in this way:}

The interconnected nature of social categorizations such as race, class, and gender as they apply to a given individual or group, regarded as creating overlapping and interdependent systems of discrimination or disadvantage

Although this study explored attitudes regarding racism, sexism, heterosexism, and Christian Privilege, it did not examine the ways in which these identities intersect and impact North American society or individual beliefs. Future research regarding these issues should include how intersectionality impacts our beliefs and ideas regarding privilege.

The second limitation for this study involves the long-term effects of the intervention. It is unknown if the intervention will have a lasting effect on the attitudes or behaviors of the pre-service foreign language teachers once they are faced with real-life classroom situations. Deficit models, discipline issues, and school policies may challenge the pre-service teachers' abilities to maintain a multicultural perspective in the classroom. Additionally, as the intervention was limited to one class period, it is unknown as to whether or not that was sufficient to maintain long term effects. To address this limitation, it is suggested that a possible longitudinal follow-up study be conducted to determine the long term effects of the one-time intervention. A final recommendation includes examining a more intense intervention, perhaps a semester-long course, for both its short- and long-term impacts on pre-service teachers.

A third limitation for this study is its uniqueness to the dominant culture specifically within the United States. Due to the historical background of colonialism in North America, white privilege in the United States is unlike that in any other colonialized country. Therefore, these concepts and findings are distinctively applicable to teacher education programs within the United States. It is unlikely that this type of research would yield similar results in other countries such as the United Kingdom or Canada.

The final limitation revolved around my own whiteness. As a white woman, I am limited in my ability to truly understand the experiences of people of color within the United States school system. It is only through my understanding of the literature and anecdotal expressions from people of color that I take my instruction about privilege and oppression. I am continually doing work on my whiteness and privilege and still consider myself a novice in these issues. Therefore, it is possible that my teachings on privilege and oppression were incomplete or in some way perpetuated a belief system that maintained white superiority, regardless of my intent. Being a white woman, I am unable to completely instruct pre-service teachers on the experiences of people of color as their voices are the only ones with that expertise. In this regard, I recommend future research be conducted by utilizing collaborations with people from a variety of backgrounds.

\subsection{Next Steps}

This study focused on pre-service foreign language teachers only and therefore lacks data to compare to the general education of pre-service teachers in the program. Although the intervention impacted the perceptions of these students, it is unknown if the changes in perception are limited to pre-service foreign language teachers or if the intervention would have had the same effect on the general education pre-service teachers. Therefore, the researchers recommend two possible follow-up studies. The first would replicate this study with pre-service teachers in a variety of disciplines. Secondly, as this study included a unique three-hour intervention distinct from the regular course curriculum, a replicate study should be conducted separately from any current course to avoid the potential of perceived coercion.

\section{Acknowledgements}

I am deeply grateful to the participants of the study for their time and willingness to participant in this research. A special thank you goes to Dr. Anne Kern for her guidance and expertise. I would like to express my gratitude towards the members of the Human Community Research Consortium for their help and feedback. Finally, I would like to thank everyone who gave permission to use the materials provided for the study. 


\section{References}

"Intersectionality." Oxforddictionaries.com. Oxford University Press, n.d. Web. 12 Nov. 2015.

American Council on the Teaching of Foreign Languages. (1999). ACTFL proficiency guidelines. Yonkers, NY: ACTFL.

Aud, S., Fox, M., \& Kewal, R. A. (2010). Status and Trends in the Education of Racial and Ethnic Groups, (NCES 2010-015). U.S. Department of Education, National Center for Education Statistics. Washington, DC: U.S. Government Printing Office.

Branscombe, N. R., Schmitt, M. T., \& Schiffhauer, K. (2007). Racial attitudes in response to thoughts of white privilege. Eur. J. Soc. Psychol., 37, 203-215. http://dx.doi.org/10.1002/ejsp.348

Castro, A. J. (2010). Themes in the research on preservice teachers' views of cultural diversity: Implications for researching millennial preservice teachers. Educational Researcher, 39(3). 198-210. http://dx.doi.org/10.3102/0013189X10363819

Chou, H. M. (2007). Multicultural teacher education: Toward a culturally responsible pedagogy. Essays in Education, 21(1), 139-162.

Cochran, S. M. (2003). The multiple meanings of multicultural teacher education: A conceptual framework. Teacher Education Quarterly, 7-26.

Dalton, H. (2012). Failing to see. In P.S. Rothenberg (ed.) White privilege: Essential readings on the other side of racism, $4^{\text {th }}$ ed. (pp.15-18). New York, NY: Worth Publishers.

Daniel, T. B. (1992). Talking about race learning about racism: The application of racial identity development theory in the classroom. Harvard Educational Review, 62(1). 1-24. http://dx.doi.org/10.17763/haer.62.1.146k5v980r703023

Gay, G. (2010). Acting on beliefs in teacher education for cultural diversity. Journal of Teacher Education, 61(1-2). 143-152. http://dx.doi.org/10.1177/0022487109347320

Gay, G., \& Kirkland, K. (2003). Developing cultural critical consciousness and self-reflection in preservice teacher education. Theory into Practice, 42(3), 181-187. http://dx.doi.org/10.1207/s15430421tip4203_3

Hayes, C., \& Juarez, B. (2012). There is no culturally responsive teaching spoken here: A critical race perspective. Democracy and Education, 20(1). Retrieved from http://democracyeducationjournal.org/home/vol20/iss1/1

Hays, D. G., \& Chang, C. Y. (2003). White privilege, oppression, and racial identity development: Implications for $\begin{array}{llllll}\text { supervision. } \quad \text { Counselor } \quad \text { Education } & \text { \& } & \text { Supervision, } & 43, & 134-145 .\end{array}$ http://dx.doi.org/10.1002/j.1556-6978.2003.tb01837.x

Holley, L. C., \& Steiner, S. (2005). Safe space: Student perspectives on classroom environment. Journal of Social Work Education, 41(1). 49-66. http://dx.doi.org/10.5175/JSWE.2005.200300343

Hooks, B. (2012). Representations of whiteness in the black imagination. In P.S. Rothenberg (ed.) White privilege: Essential readings on the other side of racism, $4^{\text {th }}$ ed. (pp. 19-24). New York, NY: Worth Publishers.

Iyer, A., Leach, C. W., \& Crosby, F. J. (2003). White guilt and racial compensation: The benefits and limits of self-focus. Personality and Social Psychology Bulletin, 29(1). 117-129. http://dx.doi.org/10.1177/0146167202238377

Kubota, R., Austin, T., \& Saito-Abbott, Y. (2003). Diversity and inclusion of sociopolitical issues in foreign language classrooms: An exploratory survey. Foreign Language Annals, 36(1), 12-24. http://dx.doi.org/10.1111/j.1944-9720.2003.tb01928.x

Marx, S. (2004). Regarding whiteness: Exploring and intervening in the effects of white racism in teacher education. Equity \& Excellence in Education, 37(1), 31-43. http://dx.doi.org/10.1080/10665680490422089

McGowan, S. L., \& Kern, A. L. (2014). Pre-service foreign language teachers' attitudes of privilege and oppression. Journal of Education and Training Studies, 1(1). 31-43. http://dx.doi.org/10.11114/jets.v2i1.188

McIntosh, P. (1988). White privilege and male privilege: A personal account of coming to see correspondences through work in women's studies (working paper no. 189). Wellesley College Center for Research on Women.

Menchaca, V. D. (1996). Multicultural education: The missing link in teacher education programs. Journal of Educational Issues of Language Minority Students, 17, 1-8.

Milner, H. R. (2006). Preservice teachers' learning about cultural and racial diversity: Implications for urban education. Urban Education, 41(4). 343-375. http://dx.doi.org/10.1177/0042085906289709

National Center for Education Statistics. Racial/Ethnic Enrollment in Public Schools: update May 2015. Retrieved from 
http://nces.ed.gov/programs/coe/indicator_cge.asp

Picower, B. (2009). The unexamined whiteness of teaching: How white teachers maintain and enact dominant racial ideologies. Race, Ethnicity and Education, 12(2), 197-215. http://dx.doi.org/10.1080/13613320902995475

Porto, M. (2010). Culturally responsive L2 education: An awareness-raising proposal. ELT Journal, 64(1), 45-53. http://dx.doi.org/10.1093/elt/ccp021

Rudnick, D. (2012). Color-blind perspective, research findings. In J. A. Banks (Ed.), Encyclopedia of diversity in education (Vol.4, pp. 408-411). Thousand Oaks, CA: SAGE Publications Ltd. http://dx.doi.org/10.4135/9781452218533.n129

Salkind, N. J. (2008). Cultural deficit model. In Encyclopedia of educational psychology, 2, 217-217. Thousand Oaks, CA: SAGE Publications Ltd. http://dx.doi.org/10.4135/9781412963848.n60

Sassi, K., \& Thomas, E. (2008). Walking the talk: Examining privilege and race in a ninth-grade classroom. English Journal, 97(6). 25-31.

Sleeter, C. E. (2001). Preparing teachers for culturally diverse schools: Research and the overwhelming presence of whiteness. Journal of Teacher Education, 52(2), 94-106. http://dx.doi.org/10.1177/0022487101052002002

Solomon, R. P., Portelli, J. P., Daniel, B. J., \& Campbell, A. (2005). The discourse of denial: How white teacher candidates construct race, racism and 'white privilege'. Race Ethnicity and Education, 8(2), 147-169. http://dx.doi.org/10.1080/13613320500110519

The Color of Fear, (1994). Summary retrieved January 15, 2012 from Internet Movie Database site (IMDB): http://www.imdb.com/title/tt0484384/plotsummary

Vaught, S. E., \& Castagno, A. E. (2008). "I don't think I'm a racist:" Critical race theory, teacher attitudes, and structural racism. Race, Ethnicity and Education, 11(2), 95-113. http://dx.doi.org/10.1080/13613320802110217

Weinstein, C. S., Tomlinson-Clarke, S., \& Curran, M. (2004). Toward a conception of culturally responsive classroom management. Journal of Teacher Education, 55(1), 25-38. http://dx.doi.org/10.1177/0022487103259812

Wildman, S. M. (2005). The persistence of white privilege. Washington University Journal of Law and Policy, 18, 245-265. Retrieved January 12, 2013 from The Washington University Law Repository: http://digitalcommons.law.wustl.edu/wujlp/vol18/iss1/11

\section{Appendix A}

Module 5: Privilege Walk Activity*

Privilege Walk statements

Purpose of the Activity:

The purpose of the Privilege Walk Activity is to learn to recognize how power and privilege can affect our lives even when we are not aware it is happening. The purpose is not to blame anyone for having more power or privilege or for receiving more help in achieving goals, but to have an opportunity to identify both obstacles and benefits experienced in our life.

*NOTE: This is a very "high risk" activity that requires trust building and safety for participants; introducing this activity too early in the training or before building trust risks creating resentment and hurt that can inhibit further sharing and openness.

\section{Supplies and Space Needed:}

List of statements related to privilege or obstacles

Slide with instructions for the privilege walk

Space large enough for participants to form a straight line with an arm's length between them and the person on their left; there should be space in front of the line to move forward 10 steps or behind to be able to move back 10 steps.

Directions for the Activity:

1) Have participants form a straight line across the room about an arm's length apart, leaving space in front and behind. 
2) State: Listen to the following statements, and follow the instructions given. For example, when I read "If you are a white male, take one step forward," only white males will move and everyone else will stand still. Each step should be an average length step. No one is going to check up on you, so if you feel you qualify to take a step then do so, if not then you may stay where you are. You are the judge of what you should do.

3) Read the statements one at a time allowing time for participants to take a step.

4) When all the statements have been read process the activity using the following questions:

What is your "gut reaction" to where you find yourself at the end of this list of privileges?

Are you surprised at where you are? How does it feel to be in front? In the middle? In back? Did you come to any new realizations? If so, which one had the most impact? 


\section{Privilege Walk Statements}

If you are a white male take one step forward.

If there have been times in your life when you skipped a meal because there was no food in the house take one step backward.

If you have visible or invisible disabilities take one step backward.

If you attended (grade) school with people you felt were like yourself take one step forward.

If you grew up in an urban setting take one step backward.

If your family had health insurance take one step forward.

If your work holidays coincide with religious holidays that you celebrate take one step forward.

If you feel good about how your identified culture is portrayed by the media take one step forward.

If you have been the victim of physical violence based on your gender, ethnicity, age or sexual orientation take one step backward.

If you have ever felt passed over for an employment position based on your gender, ethnicity, age or sexual orientation take one step backward.

If you were born in the United States take one step forward.

If English is your first language take one step forward.

If you have been divorced or impacted by divorce take one step backward.

If you came from a supportive family environment take one step forward.

If you have completed high school take one step forward.

If you were able to complete college take one step forward.

If you are a citizen of the United States take one step forward.

If you took out loans for your education take one step backward.

If you attended private school take one step forward.

If you have ever felt unsafe walking alone at night take one step backward.

Retrieved from: http://www.albany.edu/ssw/efc/pdf/Module\%205_1_Privilege\%20Walk\%20Activity.pdf

\section{Discussion Questions:}

Appendix B

Privilege Walk questions

1. What are your general reactions to the exercise? How did you feel?

2. What do you think about where you ended up in relation to where others were at the end of the exercise?

3. Were there certain "statements of privilege" that triggered certain emotions?

4. How does this information relate to you as a teacher?

5. How does this information affect you and your students?

Compliments of Kevin M. Huie, Loyola University Chicago - Diversity Training - Amazon S3 s3.amazonaws.com/os...files...77896_9544_div_privilege1.doc Retrieved from google: $\mathrm{http} / / / \mathrm{www}$. google.com/url?sa=t\&rct=j\&q=\&esrc=s\&source=web\&cd=9\&ved=0CHIQFjAI\&url=http\%3A\%2F\%2Fs3. amazonaws.com\%2Fos_extranet_files_test\%2F7896_9544_div_privilege1.doc\&ei=sQTRUJ7UPIXlyAH2yIHADA\&us $\mathrm{g}=$ =AFQjCNFunsAHPCmaVzWnN9YSUR4EDd3tqg\&sig2=6WjUYqXKxpPR2c9PuvkVEg\&bvm=bv.1355534169,d.a Wc

\section{(cc) BY}

This work is licensed under a Creative Commons Attribution 3.0 License. 